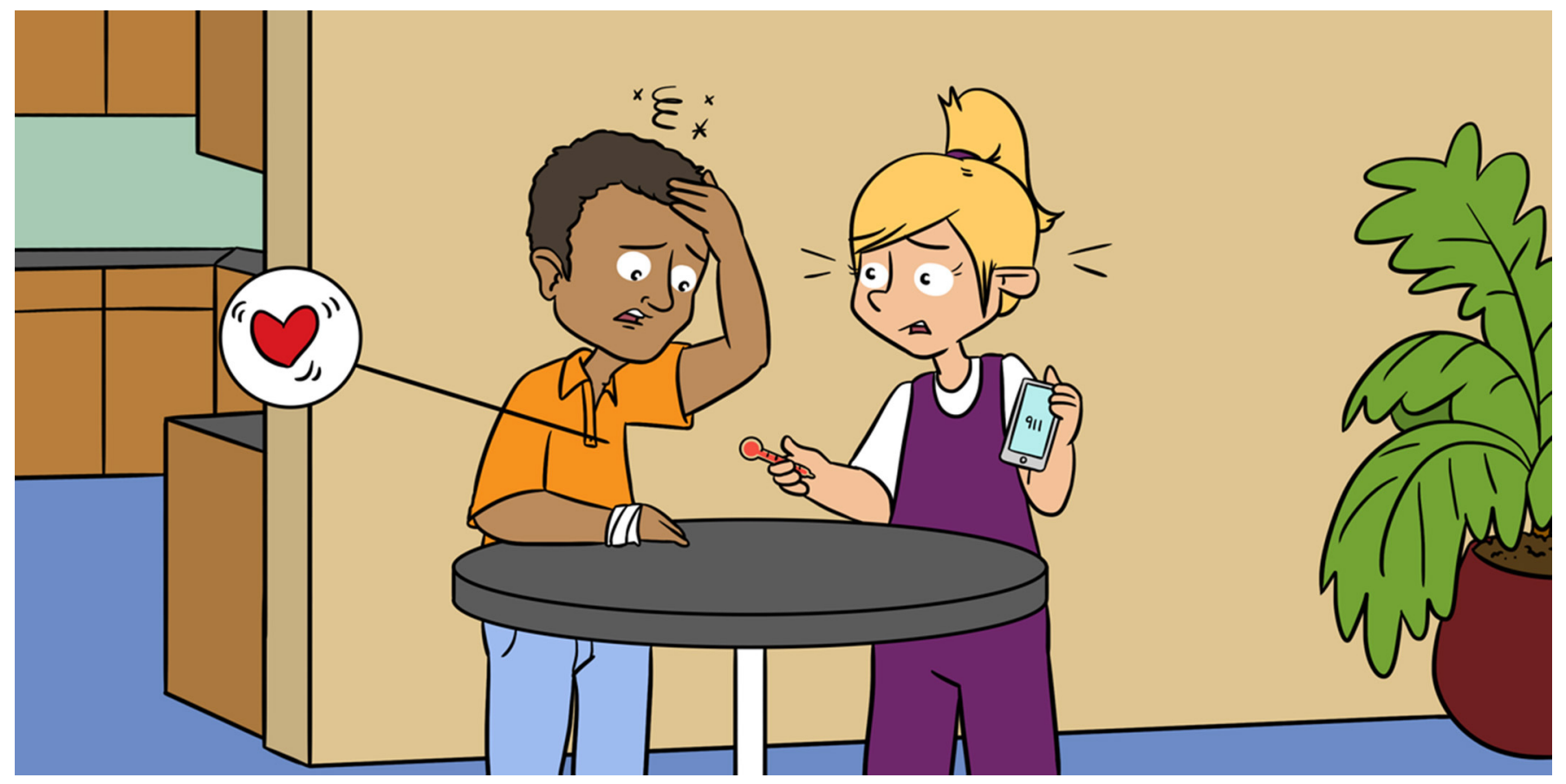

\title{
SEPSIS: WHEN A SIMPLE INFECTION BECOMES DEADLY
}

Andrew G. Farthing ${ }^{1+}$, Jessie Howell ${ }^{1+}$, J. Kenneth Baillie ${ }^{2}$, Taya Forde ${ }^{3}$, Alice Garrett ${ }^{1}$, Carl S. Goodyear ${ }^{4}$, Jennifer Gracie ${ }^{1,5}$, Colin Graham ${ }^{6}$, Tansy C. Hammarton ${ }^{4}$, Michael E. Murphy ${ }^{7,8}$, William J. Peveler ${ }^{5}$, Simon Pybus ${ }^{7}$, Mohammad Saiful Islam Sajib ${ }^{3}$, Gill Thomson ${ }^{6}$ and Melanie Jimenez ${ }^{1 *}$

1 James Watt School of Engineering, University of Glasgow, Glasgow, United Kingdom

${ }^{2}$ Genetics and Genomics, Roslin Institute, University of Edinburgh, Edinburgh, United Kingdom

3 Institute of Biodiversity, Animal Health \& Comparative Medicine, University of Glasgow, Glasgow, United Kingdom

${ }^{4}$ Institute of Infection, Immunity and Inflammation, University of Glasgow, Glasgow, United Kingdom

${ }^{5}$ School of Chemistry, University of Glasgow, Glasgow, United Kingdom

${ }^{6}$ Sepsis Research FEAT, Glasgow, United Kingdom

${ }^{7}$ National Health Service Greater Glasgow and Clyde Glasgow Royal Infirmary, Clinical Microbiology, Glasgow, United Kingdom ${ }^{8}$ School of Medicine, Dentistry and Nursing, College of Medical, Veterinary and Life Sciences, University of Glasgow, Glasgow, United Kingdom

\section{YOUNG REVIEWERS:}

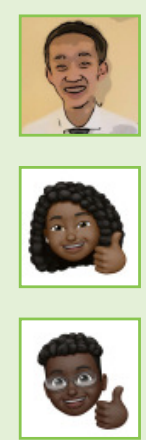

ETHAN

AGE: 15

JADA

AGE: 14

JOSHUA

AGE: 14
The immune system plays a crucial role in maintaining a healthy body by working around the clock to recognize and respond to infection. Inflammation is part of the immune system's protective response to an infection. The inflammatory response is incredibly powerful, so much so that it can damage the body's cells if it is not tightly controlled. Sometimes, inflammation affects the whole body-this is called sepsis. The powerful and complex mechanisms in place to wipe out the infection can cause serious damage to healthy cells and 


\section{SEPSIS}

An illness where the body's immune system overreacts to a simple infection.

\section{PATHOGEN}

An infectious agent that can make us sick and cause disease. Bacteria, fungi, parasites, and viruses are examples of pathogens.

1 https://www. sepsisresearch. org.uk/aboutus/what-is-sepsis/ tissues. Uncontrolled inflammation can cause irreversible damage to the body's organs, such as the kidneys, eventually causing organs to shut down. If sepsis is not treated rapidly, it can lead to death. In this article, we describe the symptoms and diagnosis of sepsis and some of the current research being performed to better understand this dangerous process.

\section{SEPSIS: A DANGEROUS RESPONSE TO AN INFECTION}

Sepsis is an illness where the body overreacts to a simple infection. Sepsis is responsible for about 11 million deaths per year worldwide. This accounts for roughly $20 \%$ of all global deaths, which is even more than from breast and bowel cancers combined [1].

Sepsis is caused by an infection from invading pathogens, such as viruses, bacteria, parasites, or fungi, which either come from the environment or even from within our own bodies. Common infections that can lead to sepsis include meningitis (infection of the linings of the brain), pneumonia (infection of the lungs), urinary tract infections (infections of the bladder or kidneys) and cellulitis (infection of the skin, often affecting the foot and leg). However, an infection anywhere in the body has the potential to cause sepsis.

The symptoms of sepsis include ${ }^{1}$

- Fever (high temperature)

- Difficulty breathing

- Rapid heart rate

- Decreased urine production

- Confusion and/or slurred speech

- Cold and/or blotchy hands and feet (mottled skin)

Once sepsis begins, deterioration in physical health can happen incredibly quickly-in just a few hours-so it is crucial to recognize the symptoms of sepsis before it is too late. To understand sepsis and its symptoms, we need to look at the immune system, to see how it works normally and what goes wrong during sepsis.

\section{THE IMMUNE SYSTEM AND INFLAMMATION}

The immune system consists of a very complex network of different chemicals and cells, all working together to recognize dangerous pathogens, kill them, neutralize their toxins, and maintain a healthy body. To do this, the body has two weapons, which scientists call the innate immune system and the adaptive immune system. Think of them like a grenade and a sniper: the innate immune system 


\section{INFLAMMATION}

A response by the body's immune system to fight an infection. Characterized by heat, pain, redness, and swelling.

\section{VASODILATION}

When blood vessels become wider as part of the inflammatory response.

\section{VASCULAR}

\section{PERMEABILITY}

Leaky blood vessels, which allow immune cells to get into the surrounding tissue as part of an inflammatory response.

\section{RECEPTOR}

A protein naturally found on the surface of cells and blood vessels which are able to bind and capture cells and pathogens. They can be adapted for research purposes.

\section{SYSTEMIC}

Relating to the whole body as opposed to a single location.

damages whatever is in range, while the adaptive immune system homes in with precision, as a sniper would hunt down an enemy. We will focus on the innate immune system. The innate immune system acts immediately and locally; it rapidly employs a cocktail of potent chemicals and mechanisms to contain the infection before it has a chance to do any significant damage. When the innate immune system senses the presence of a pathogen, immune cells send out chemical signals to warn other cells of an invasion and release a host of toxic chemicals to try and kill the invading pathogen. Inflammation is one of the mechanisms used by the innate immune system to fight infections.

Think of getting a papercut: microscopic pathogens enter the wound and it becomes swollen and sore; that means there is inflammation. Inflammation is necessary to help the body recover from injury and infection [2]. An inflammatory immune response causes vasodilation and increased vascular permeability at the wound site, meaning blood vessels dilate (widen) and become leaky, causing blood flow to slow down in that area. At the site of inflammation, special proteins, called receptors, are produced on the inside of blood vessels that act like hooks to capture cells of the immune system as they pass by. Slower blood flow makes it easier for more of these cells to get to the site of injury/infection, and the leaky blood vessels help them to pass through blood vessel walls into the site of infection.

\section{SEPSIS: WHEN INFLAMMATION GOES WRONG}

The exact cause of sepsis is not known. Most of the time, the immune system can efficiently take care of an infection without a problem. However, during sepsis, the inflammatory response of the innate immune system is not restricted to the location of the infection-it "goes rogue," leading to systemic inflammation, which is inflammation all over the body. Instead of being contained at the site of infection, inflammatory chemicals are released into the bloodstream and travel throughout the body, where they cause widespread vasodilation and increased vascular permeability in the blood vessels. This results in a drop in blood pressure, which causes inadequate blood flow to the body's tissues and organs. Blood transports oxygen to the organs, so a lack of blood flow decreases the amount of oxygen organs receive, affecting their functions.

Systemic inflammation and decreased blood flow cause a range of serious symptoms. Each of the organs can be affected in a unique way. To compensate for the inadequate blood flow, the heart and lungs must work much harder to supply the tissues with oxygenated blood, resulting in a faster heart rate and breathing difficulties. Furthermore, the lungs become less efficient at oxygenating the blood, as inflammation causes fluid to collect in the lung cavities and 
Figure 1

Normal

inflammation compared to sepsis. In a normal inflammatory response, a person with an injured hand would experience symptoms only in the area around the wound. However, in sepsis, the response affects the entire body and can be extremely dangerous, sometimes leading to organ failure and death.

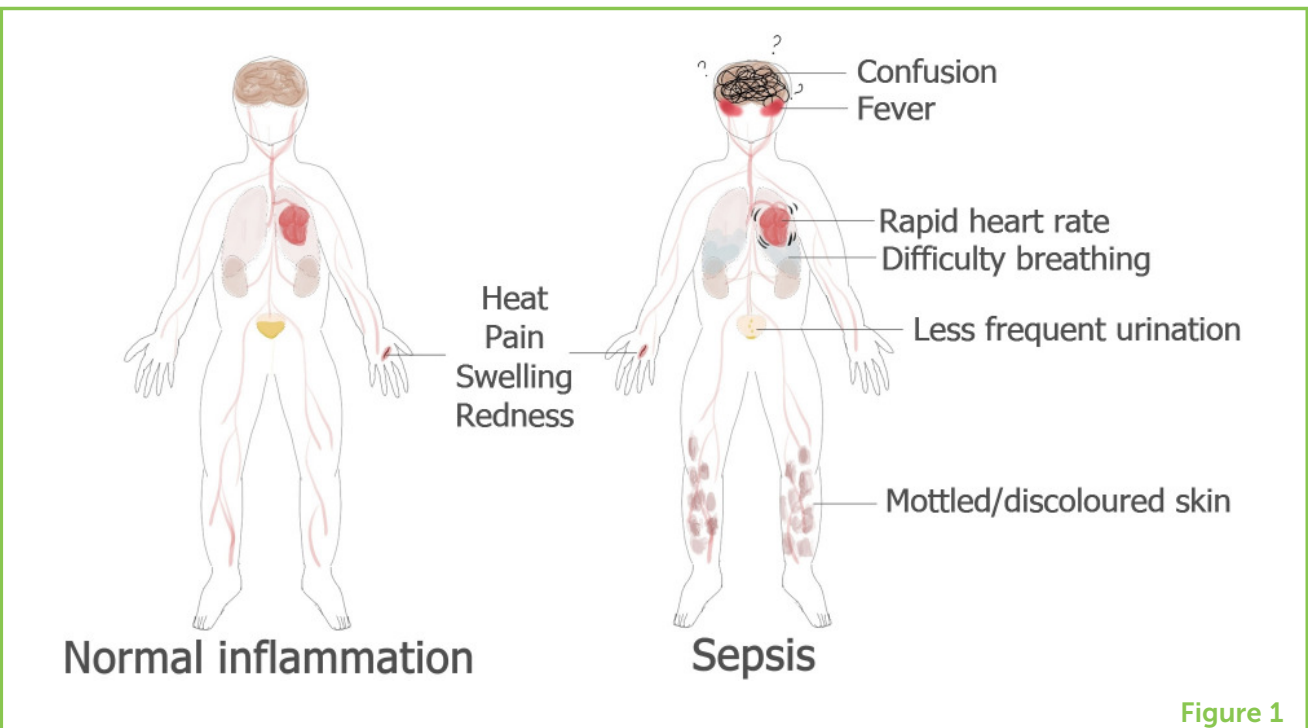

tissues. This means that less oxygen is available in the blood for the body's organs.

The kidneys are responsible for filtering excess water and toxins out of the blood, in the form of urine. Sepsis-associated inflammation and impaired blood flow affect the kidneys' ability to clean the blood and make urine. Pale or mottled skin is a sign that the skin is not getting enough oxygenated blood. Confusion and slurred speech in sepsis patients are caused by changes happening in the brain. Scientists do not know for sure why confusion happens in sepsis, but they think it might have to do with the brain not getting enough oxygen, or it might be caused by chemicals released by cells of the immune system [2]. When inflammatory signals reach the hypothalamus, an area of the brain that regulates body temperature, this causes fever. Fever is a common sign of an inflammatory response to infection; the patient will have an elevated temperature, whilst feeling hot and flushed or cold and shivery $[3,4]$.

These are all examples of ways sepsis can affect the body (Figure 1), but sepsis is much more dangerous than this. Importantly, during sepsis, normal organ functions can only be sustained for a limited time before the organs become irreversibly damaged and start shutting down, eventually leading to death.

\section{HOW DO WE DIAGNOSE AND TREAT SEPSIS?}

Scientists have shown that time is critical in treating patients with sepsis. The earlier the treatment, the better their chances of survival. Figure 2 provides a summary of the tests used to diagnose sepsis. 
Figure 2

A patient with suspected sepsis may be given intravenous fluids and oxygen. Urine output and the levels of oxygen, lactate, and C-reactive protein (CRP) in the blood are monitored, to assess the severity of infection.

Broad-spectrum antibiotics are used as a first line of defense. To identify the pathogen, a blood sample is cultured until the pathogen reaches a concentration that can be detected. Only at this point can the patient be treated with specific antibiotics.

\section{ANTIBIOTIC}

A drug that targets bacteria. Some antibiotics are broad spectrum, meaning they work on lots of bacteria, whereas some are more specific.

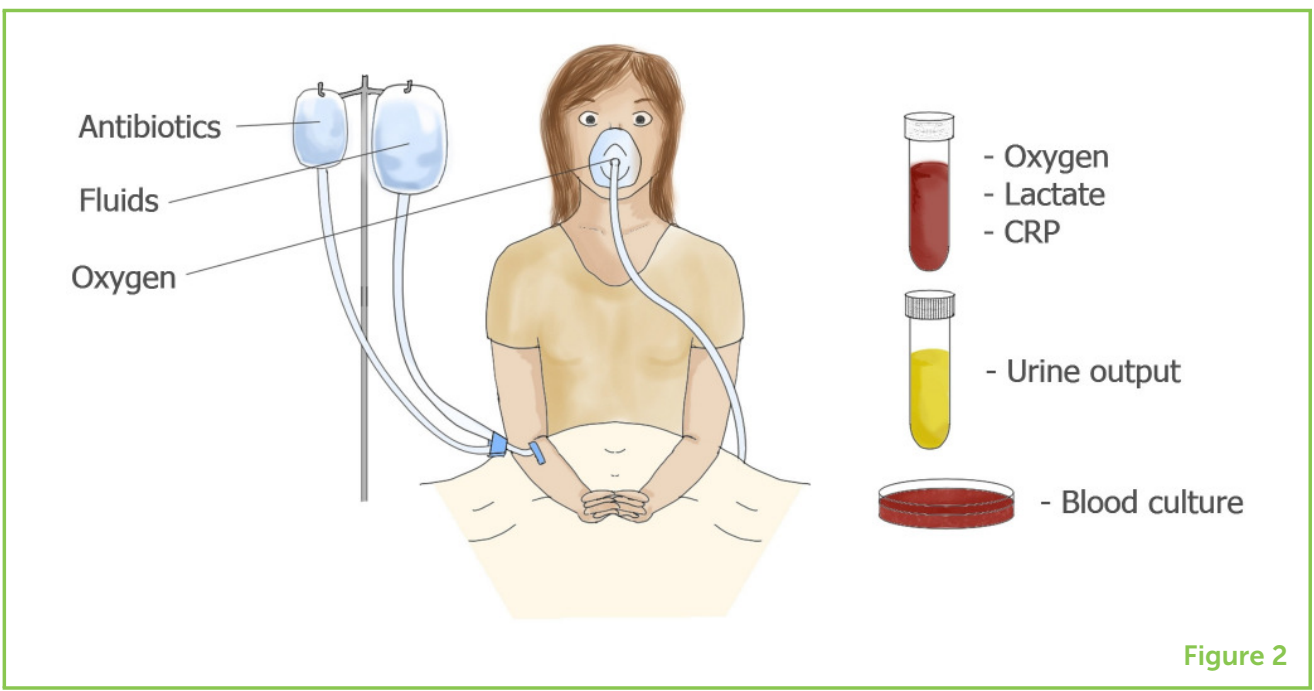

Patients suspected of having sepsis are kept under close observation. Blood pressure and blood oxygen content are monitored. Urine output is monitored to make sure the kidneys are functioning properly. Patients are immediately treated with broad-spectrum antibiotics, to try to kill the pathogens that might be responsible for the infection. They might also receive oxygen or fluids, depending on their condition. Blood will also be taken for laboratory tests to diagnose sepsis. Several molecules in the blood can indicate what is happening in the body. These include C-reactive protein, which is produced by innate inflammatory cells, procalcitonin, which suggests the presence of a bacterial infection (as opposed to viral or fungal infections), and lactate, which is produced in high levels when the body's cells are under stress.

Another test done on patients with suspected sepsis is to try to find pathogens in their blood. Because a blood sample has a really high number of blood cells, finding pathogens can be like finding a needle in a haystack; the blood sample must first be cultured for 1-5 days, until the number of pathogens reaches a concentration high enough that they can be identified. Once the pathogen is identified, the patient can be given antibiotics that can specifically kill the pathogen responsible for the infection. This is a time-consuming process that we, as researchers, aim to improve. Quick identification of the pathogen causing the infection would allow patients to receive the most appropriate treatment more rapidly.

\section{CURRENT SEPSIS RESEARCH}

To find pathogens in blood samples, we are engineering microscopic magnetic beads that can recognize various pathogens. When we mix these beads with a blood sample from a patient, the beads will bind to the pathogens and, thanks to the magnetic properties of the beads, we can remove the beads and the pathogens with a magnet (Figure 3A). 
Figure 3

(A) Magnetic particles coated in receptors are being developed to capture pathogens in a blood sample. The pathogens can be separated along with the particles, using a magnet. (B) DNA can be removed from the pathogens and "read" to determine the identity of the pathogen and whether it is resistant to any antibiotics [5]. (C) Patterns in human DNA can also be studied to better understand why some people develop sepsis while others do not.

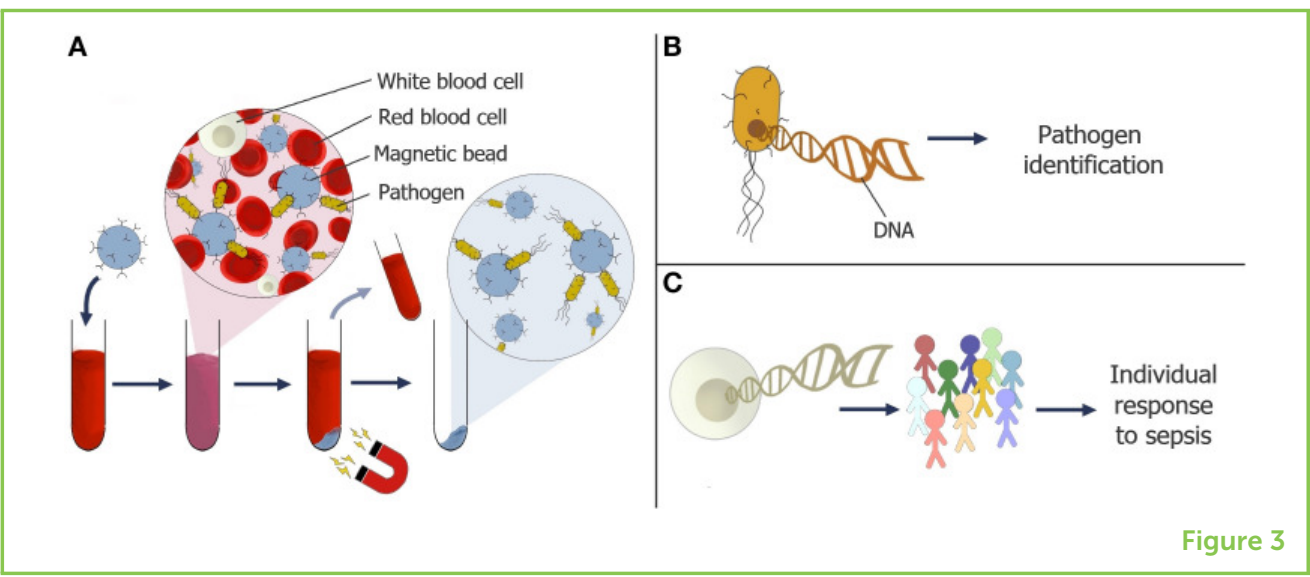

Although our beads will bind to the pathogens, we still need to identify the pathogens once they are separated from the blood sample. We do that by extracting and sequencing DNA and then looking for genetic information that is unique to pathogens, kind of like reading a barcode (Figure 3B). With the help of some sophisticated software [5], we can determine not only the identity of the pathogen but also to how it might react to various treatments. This part of our work aims to help doctors know, as quickly as possible, what might have caused sepsis and what the best treatment for a patient is.

Importantly, identifying the pathogen is not the only key to a patient's survival. We are still trying to understand why an infection might turn into sepsis for one person and not for another. In a separate study, we are studying human DNA sequences from blood samples of many sepsis patients, to see if we can recognize specific patterns for people who have had sepsis. Using powerful computers, we are trying to identify what these patients have in common (Figure 3C). The goal of our research is to better understand why some people are more at risk of sepsis than others, and to make sure they can receive the best treatments as quickly as possible if they do have sepsis.

\section{CONCLUSION}

The immune response is crucial for maintaining a healthy body. However, systemic inflammation can cause some very serious problems, which are seen in the case of sepsis. Sepsis can eventually cause multiple organ failure and death, but this can be avoided if sepsis is rapidly diagnosed and doctors quickly prescribe the right treatment to target the pathogen. The good news is that, if doctors give the right treatment quickly, most people will get better; therefore it is incredibly important that everyone learns to recognize the signs of sepsis. Hopefully, our research will help doctors to diagnose sepsis more rapidly providing patients with faster and more specific treatment. As time is crucial when treating patients with sepsis, this research may help to save the lives of many people. 


\section{REFERENCES}

1. Rudd, K. E., Johnson, S. C., Agesa, K. M., Shackelford, K. A., Tsoi, D., Kievlan, D. R., et al. 2020. Global, regional, and national sepsis incidence and mortality, 1990-2017: analysis for the Global Burden of Disease study. Lancet 395:200-11. doi: 10.1016/S0140-6736(19)32989-7

2. Sonneville, R., Verdonk, F., Rauturier, C., Klein, I. F., Wolff, M., Annane, D., et al. 2013. Understanding brain dysfunction in sepsis. Ann. Intensive Care 3:15. doi: 10.1186/2110-5820-3-15

3. van der Poll, T., van de Veerdonk, F. L., Scicluna, B. P., and Netea, M. G. 2017. The immunopathology of sepsis and potential therapeutic targets. Nat. Rev. Immunol. 17:407-20. doi: 10.1038/nri.2017.36

4. Pool, R., Gomez, H., and Kellum, J. A. 2018. Mechanisms of organ dysfunction in sepsis. Crit. Care Clin. 34:63-80. doi: 10.1016/j.ccc.2017.08.003

5. Jain, M., Olsen, H. E., Paten, B., and Akeson, M. 2016. The Oxford Nanopore MinION: delivery of nanopore sequencing to the genomics community. Genome Biol. 17:239. doi: 10.1186/s13059-016-1103-0

SUBMITTED: 09 December 2020; ACCEPTED: 20 April 2021; PUBLISHED ONLINE: 21 May 2021.

EDITED BY: Michel Goldman, Institute for Interdisciplinary Innovation in healthcare (I3h), Belgium

CITATION: Farthing AG, Howell J, Baillie JK, Forde T, Garrett A, Goodyear CS, Gracie J, Graham C, Hammarton TC, Murphy ME, Peveler WJ, Pybus S, Sajib MSI, Thomson G and Jimenez M (2021) Sepsis: When a Simple Infection Becomes Deadly. Front. Young Minds 9:639681. doi: 10.3389/frym.2021.639681

CONFLICT OF INTEREST: The authors declare that the research was conducted in the absence of any commercial or financial relationships that could be construed as a potential conflict of interest.

COPYRIGHT @ 2021 Farthing, Howell, Baillie, Forde, Garrett, Goodyear, Gracie, Graham, Hammarton, Murphy, Peveler, Pybus, Sajib, Thomson and Jimenez. This is an open-access article distributed under the terms of the Creative Commons Attribution License (CC BY). The use, distribution or reproduction in other forums is permitted, provided the original author(s) and the copyright owner(s) are credited and that the original publication in this journal is cited, in accordance with accepted academic practice. No use, distribution or reproduction is permitted which does not comply with these terms.

\section{YOUNG REVIEWERS}

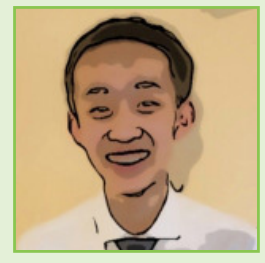

\section{ETHAN, AGE: 15}

Hi! My name is Ethan. At my regional science fair, I won Best Junior Project, Best Biology Project, Gold Medal, and a qualification to the Canada-Wide Science Fair, where I achieved a bronze medal. I have also been a finalist at the InspoScience 

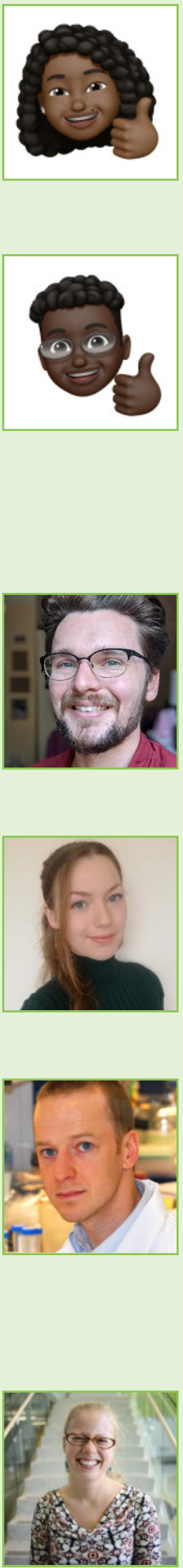

Canada IRIC. Besides, I enjoy debating, having won the title of national champion and second speaker this past year, and public speaking. I am an avid writer, being published for my poems, short stories, and argumentative articles.

\section{JADA, AGE: 14}

Hi! My name is Jada from Atlanta, GA. In my free time, I like to draw/sketch, listen to music, write short stories, and watch an array of movies. I play lacrosse, and I swam for about 5 years. When I become older, I want to be a Cosmetic Plastic Surgeon because I want to make all of my patients proud of their bodies and not insecure about themselves. Helping others is one of my motivations in life!!!

\section{JOSHUA, AGE: 14}

I am a rising ninth grader and I live in Atlanta, Georgia. During the academic school year I participate in many programs including the Academic team and the Lacrosse team. When I am not studying or at school I love to read books and play lacrosse. I am happy to be a part of this program because I enjoy science, and I am happy that my feedback is so important in helping people publish their articles.

\section{AUTHORS}

\section{ANDREW G. FARTHING}

Andrew Farthing is a Ph.D. student at the University of Glasgow, UK. His research is focused on developing new methods to rapidly enrich pathogens from blood samples to speed up the process of pathogen identification for people suspected of having sepsis. The faster the identity of the pathogen can be found, the sooner a patient can be treated with antibiotics that specifically target their infection.

\section{JESSIE HOWELL}

Jessie Howell is a Ph.D. student at the University of Glasgow, UK. She has a background in immunity and infection and is currently developing methods to separate parasites based on their size and shape. Isolating pure populations of cells makes studying them much easier, aiding further research into their mechanisms of infection and methods of treatment.

\section{J. KENNETH BAILLIE}

Dr. Kenneth Baillie is a consultant in the intensive care unit at the Royal Infirmary, Edinburgh, and leads a research programme at the Roslin Institute, University of Edinburgh, to better understand the role of genomics in critical care medicine. He completed basic training in medicine in Glasgow and in anesthesia in Edinburgh. During this time, he led a series of high-altitude research projects in Bolivia and founded a high-altitude research charity, Apex. Currently, Kenny's research group works on topics, such as sepsis, influenza, and COVID-19.

\section{TAYA FORDE}

Dr. Taya Forde is a veterinary researcher who uses bacterial sequence data to address questions related to pathogen transmission. Many of her studies are at the interface between humans, animals, and the environment, a concept known as "One Health." She is interested in developing methods to sequence pathogens directly 

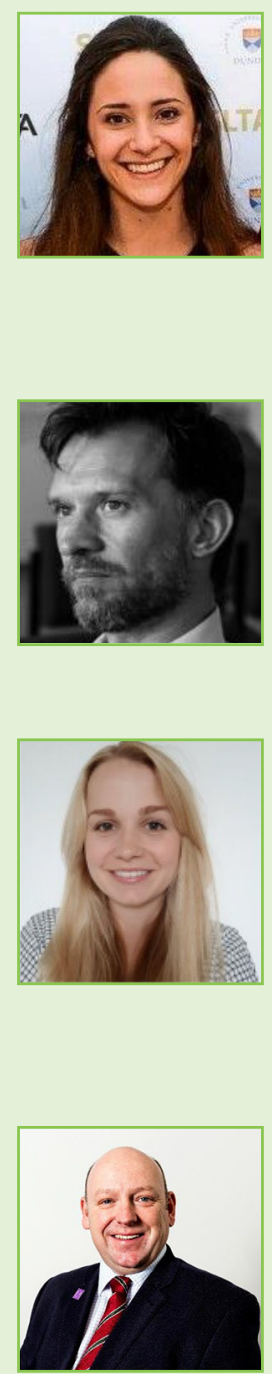

\section{ALICE GARRETT}

Alice Garrett is a biomedical engineering Ph.D. student at the University of Glasgow, UK, who has worked on new platforms to aid the molecular detection of pathogens. Her work focuses on finding solutions for point-of-care tests that detect pathogen DNA, to diagnose diseases, such as malaria and schistosomiasis in rural areas with limited access to healthcare. Alice is currently working on the frontlines, processing molecular tests in the laboratory to screen for COVID-19.

\section{CARL S. GOODYEAR}

Prof. Carl Goodyear's research group at the University of Glasgow is focused on understanding immunopathogenesis of diseases like arthritis, and translating this knowledge into therapeutic agents for patients. In parallel, he also leads a Translational Immunology programme, which provides the critical interface between clinical and basic science.

\section{JENNIFER GRACIE}

Dr. Jennifer Gracie is a research associate at the University of Glasgow, where she is developing a test to speed up the diagnosis of sepsis in hospitals. Using her experience in nanotechnology and chemistry, alongside colleagues with expertise in biology and biomedical engineering, she hopes to reduce the time taken to diagnose sepsis in critically ill patients. Jenny's background is in chemistry, and she obtained Ph.D. and master's degrees from the University of Strathclyde.

\section{COLIN GRAHAM}

Colin Graham joined Sepsis Research in October 2018, as the charity's first Chief Operating Officer. He is responsible for developing awareness of the charity, overseeing its fundraising and marketing strategy, and developing strategic partnerships. Prior to joining Sepsis Research, Colin worked as the CEO at Cancer Support Scotland, as area fundraising manager for Breast Cancer Care, and as head of fundraising for Erskine Hospital. He started his career as a fundraiser for Macmillan Cancer Care.

\section{TANSY C. HAMMARTON}

Dr. Tansy Hammarton is a senior lecturer and parasitologist at the University of Glasgow, Scotland. Her lab studies tiny parasites that cause the nasty and often fatal tropical diseases called sleeping sickness and leishmaniasis, which affect some of the worlds' poorest people. Her group researches how these parasites grow and multiply, and tries to identify essential molecules that could be targeted by novel drugs. Tansy also really enjoys discussing science with members of the public, especially school pupils.

\section{MICHAEL E. MURPHY}

Dr. Michael E. Murphy trained as a medical doctor and became interested in infection, undertaking further specialized training in London, Oxford, and Cambridge, as well as periods working in Tanzania, South Africa, and India. He returned to Glasgow, where he works as a consultant microbiologist at the hospital, diagnosing and treating patients with infections. He is also a researcher at the University of Glasgow, with 

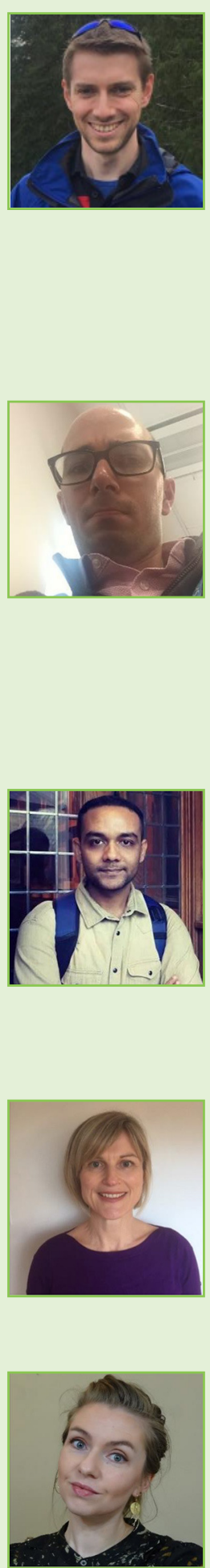

an interest in using technological advances to speed up the diagnosis of a wide range of infections, as well as evaluating how these tests can be used to improve patient care.

\section{WILLIAM J. PEVELER}

Dr. William Peveler is a LKAS Fellow in the School of Chemistry at the University of Glasgow. Will and his team (the Bio Nano Sensing Group) exploit cutting edge molecular- and nano-technologies to build new sensors. Current projects include developing sensors for detecting sepsis and liver disease, as well as a range of other diseases and infections. Their research brings together chemistry, biomedicine, and engineering to solve these sensing challenges. Will studied chemistry at the University of Oxford and was awarded his Ph.D. from University College London.

\section{SIMON PYBUS}

Dr. Simon Pybus is undertaking specialized training in medical microbiology and infectious diseases, working in Glasgow, UK. Simon studied medicine and completed his initial clinical training in Liverpool, UK. Early on, he gained a strong interest in infection and antibiotic therapy. Simon treats patients with sepsis on a daily basis. He also provides advice to other doctors on optimal management of a variety of infections, including bloodstream infections, guided by laboratory results. Simon is passionate about improving laboratory techniques to provide high quality patient care.

\section{MOHAMMAD SAIFUL ISLAM SAJIB}

Mohammad Saiful Islam Sajib's research focuses primarily on infectious diseases, and he aims to improve public health by generating evidence for future policy decisions. He worked as a microbiologist in the Child Health Research Foundation in Bangladesh for 4 years. Currently, as a Ph.D. student at the University of Glasgow, he is utilizing clinical metagenomics to diagnose sepsis, to improve patient outcomes and reduce antimicrobial resistance.

\section{GILL THOMSON}

Gill Thomson is the fundraising, finance, and administration co-ordinator for Sepsis Research. She is the main point of contact for supporters and enquiries. She joined Sepsis Research in June 2019. Gill supports Colin Graham in the delivery of the charity's research and awareness objectives, and she engages with as many supporters as possible to help them with fundraising initiatives.

\section{MELANIE JIMENEZ}

Dr. Melanie Jimenez studied engineering in France and is now a researcher in biomedical engineering at the University of Glasgow. Melanie works with clinicians, chemists, biologists, and social scientists to develop new medical diagnostic tools for a healthier nation. More specifically, Melanie and her group are engineering new technologies - at the interface of physics, chemistry, and biology-that can rapidly recognize pathogens in patient samples, to help health professionals treat infected patients faster. *melanie.jimenez@glasgow.ac.uk

${ }^{\dagger}$ These authors have contributed equally to this work 